\title{
PREDICTED PERCENTAGE DISSATISFIED (PPD) MODEL EVALUATION OF EVAPORATIVE COOLING POTENTIALS OF SOME SELECTED CITIES IN NIGERIA
}

\author{
U. H. Ibrahim ${ }^{1,}{ }^{*}$, C. Nathan ${ }^{2}$ and A. Ayuba ${ }^{3}$ \\ 1,2,3 Department of Mechanical Engineering, Federal Polytechnic Mubi, Adamawa State, Nigeria \\ E-mail addresses: ${ }^{1}$ heldabuk@yahoo.com, 2 chindapi@gmail.com,3arhelayuba@gmail.com
}

\begin{abstract}
In some developing nations like Nigeria, poverty and epileptic power supply are the twin problems impeding people from the use of refrigeration-based air conditioning systems to achieve thermal comfort. Direct evaporative cooling is a viable option of achieving thermal comfort especially in hot and dry climates. Direct evaporative coolers, apart from their low power requirements, are relatively cheap and are environment friendly. This paper attempts to estimate the direct evaporative cooling potential of some selected cities in Nigeria using the predicted percentage dissatisfied (PPD) model. The model stipulates that a conditioned space is thermally comfortable if not more than 20\% of the occupants are thermally unsatisfied. These selected cities are Enugu, Kano, Jos, Maiduguri and Mubi-South. The computed PPD for the months of January through December for the selected cities were determined. The computed PPD of these cities reveal the suitability of using evaporative coolers in the months of January and December for Enugu; all the twelve months for Kano; January, February, March, April, May, September, October, November and December for Jos; January, February, March, April, May, June, October, November and December for Maiduguri and, all the twelve months for Mubi-South, because their computed PPD in these months are less than 20\%. This, however, shows that there is high potential of using direct evaporative coolers in Kano, Jos, Maiduguri and Mubi-South which can be attributed to the relative high outdoor temperatures and low relative humidity. Apart from Enugu, direct evaporative coolers are recommended in these areas and in areas with similar climatic characteristics.
\end{abstract}

Keywords: Predicted percentage dissatisfied, Evaporative cooling, Thermal comfort, Predicted mean vote

\section{INTRODUCTION}

Thermal comfort is the condition of mind that expresses satisfaction with the thermal environment and environmental and personal factors need to be taken into account when deciding what will make people feel comfortable. The best one realistically hopes to achieve is a thermal environment that satisfies the majority of people in an occupied space [1]. Studies have shown that $80 \%$ of occupants is a reasonable limit for the minimum number of people who should be thermally comfortable in an environment [2]. There are passive, active and hybrid means of achieving thermal comfort. The passive methods of achieving thermal comfort such as the use of shading devices, natural ventilation, nocturnal thermal radiation, etc., to a reasonable degree can only provide relief comfort for the occupants of a space [3]. In extreme weather conditions, active systems such as refrigerated-based air conditioning systems are used to condition the air and make it suitable for human thermal comfort. However, the use of the refrigeration-based air conditioning systems is associated with problems such as [4]:

- They are not fully utilized in areas where power supply is epileptic and constantly interrupted

- They are relatively expensive compared with the refrigeration-based air conditioning systems

- $\quad$ They are characterized by poor indoor air quality because of the use of recirculated air

- The high electric power consumption translates to high operational cost

- Their maintenance require the service of a skilled personnel; and

- Restrictions imposed by protocols limit the type of refrigerants that can be used.

Direct evaporative cooling offers an economical, energy efficient and practical means of cooling and can be used to maximum advantage in areas having high dry bulb 
temperatures and low outdoor relative humidity. Other benefits of direct evaporative cooling are:

- Unlike refrigeration-based cooling systems that rely on recycled cooled air with partial fresh air replacement, direct evaporative cooling enjoys popularity because of the introduction of a continuous supply of freshly cooled outdoor air. This creation of healthy invigorating conditions generates a feeling of relaxed enthusiasm, conducive to improve occupant's concentration and work output. This is due to the naturally cooled, humidified, negatively ionized air which does not dry up nasal passages, eyes or skin, unlike the positively ionized, artificially cooled air from a refrigeration-based air conditioning [4].

- Helps maintain natural humidity levels, which benefits both people and furniture and cuts static electricity

- Does not need an air-tight structure for maximum efficiency, so building occupants can open doors and windows

- Direct evaporative cooling is an inexpensive cooling option. It is up to $50 \%$ cheaper to install and seven times cheaper to run than refrigeratedbased cooling [4].

- The working fluid, water, is readily available and does not have negative impact on the environment.

The performance of direct evaporative coolers is a function of climatic parameters such as the ambient dry bulb temperature, wet bulb temperature, relative humidity and wind speed. This paper attempts to estimate the direct evaporative cooling potential of some selected cities in Nigeria: Enugu, Kano, Jos, Maiduguri and Mubi-South, using the predicted percentage dissatisfied (PPD) model. These cities are

\section{DESCRIPTION OF THE EVAPORATIVE COOLER}

In direct evaporative cooling, non-saturated air comes into contact with water-saturated cooling pad, and evaporation occurs. The necessary latent heat is provided by the air, which cools down. In addition, the moisture content of the air rises. Direct evaporative cooling is represented on the psychrometric chart in figure 1 by a displacement along a constant wet bulb temperature line $\mathrm{PQ}$.

\section{PREDICTIVE MEAN VOTE}

The predictive mean vote (PMV) is a parameter for assessing thermal comfort in an occupied zone based on the conditions of metabolic rate, clothing, air speed besides temperature and relative humidity [2]. The PMV is expressed on the 7-point ASHRAE scale of thermal sensation [11]. The scale ranges from -3 to +3 as shown in Table 1.

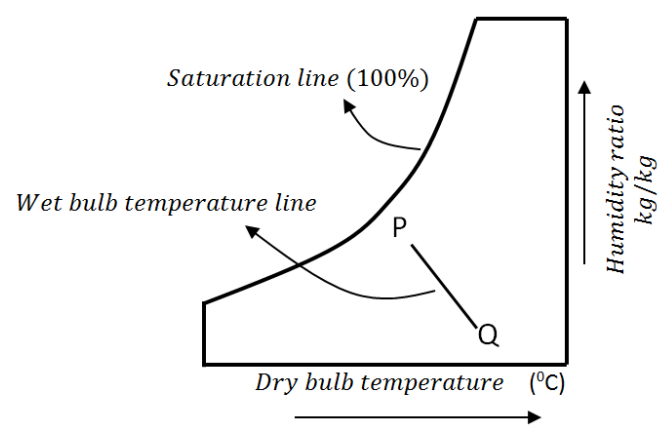

Figure 1: Direct Evaporative Cooling

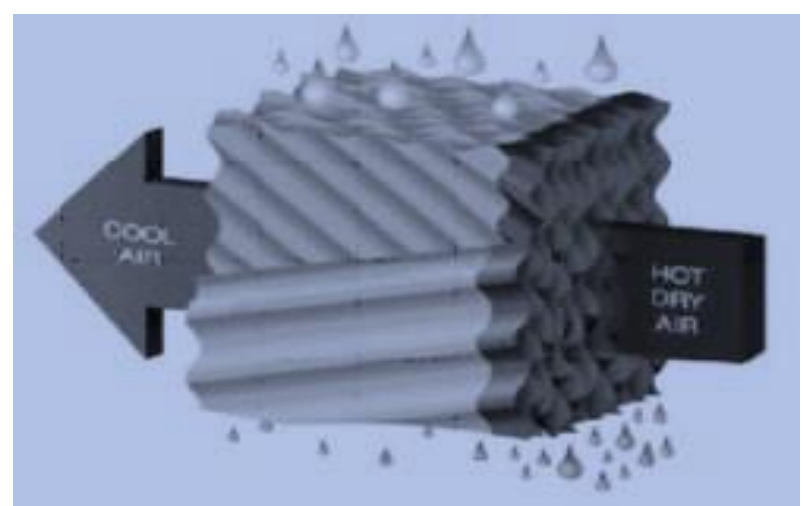

Figure 2: Evaporative Cooling Pad of DEC

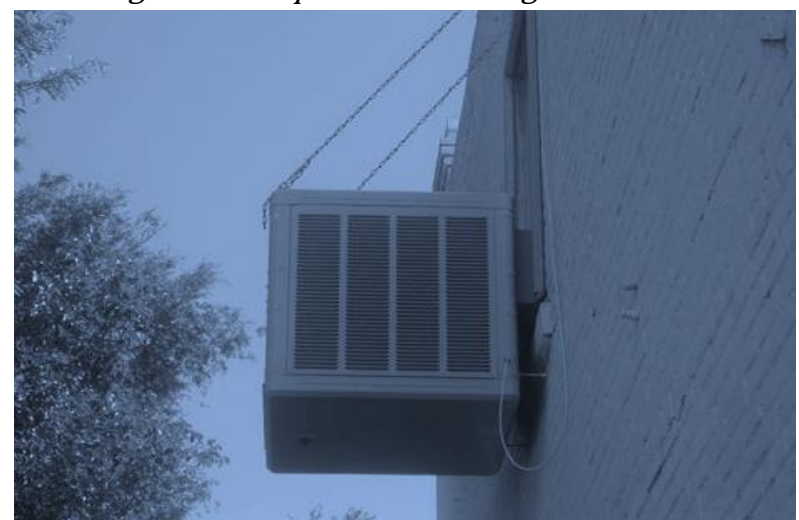

Figure 3: DEC Window Installation

Table 1: Scale of Thermal Sensation [2]

\begin{tabular}{lc}
\hline Thermal Sensation & Numerical Value \\
\hline Much too warm & +3 \\
Too warm & +2 \\
Comfortably warm & +1 \\
Comfortable & 0 \\
Comfortably cool & -1 \\
Too cool & -2 \\
Much too cool & -3 \\
\hline
\end{tabular}

The general comfort equation developed by Fanger[ 5] to describe the conditions under which a large group of people will feel in thermal neutrality is too complex and cannot be used in real time applications unless

Vol. 37, No. 1, January 2018 
being simplified. Equations 1-3 show the comfort equation proposed by Fanger [6].

$$
\begin{aligned}
& P M V=(0.028+\left.0.3033 e^{-0.036}\right)\{(M-W) \\
&-3.05[5.733-0.000699(M-W) \\
&\left.-P_{a}\right]-0.42[(M-W)-58.15] \\
&-0.0173 M\left(5.867-P_{a}\right) \\
&-0.0014 M\left(34-T_{a}\right)-3.96 \\
& \times 10^{-8} f c l\left[\left(T_{c l}+273\right)^{4}\right. \\
&\left.-\left(T_{m r t}+273\right)^{4}\right] \\
&\left.-f c l . h_{c}\left(T_{c l}-T_{a}\right)\right\} \\
& \\
& T_{c l}=35.7-0.028(M-W) \\
&-0.155 I_{c l}[3.96 \\
& \times 10^{-3} f c l\left[\left(T_{c l}+273\right)^{4}\right. \\
&\left.-\left(T_{m r t}+273\right)^{4}\right] \\
&\left.-f c l . h_{c}\left(T_{c l}-T_{a}\right)\right] \\
& h_{c}=\left\{\begin{array}{l}
2.38\left(T_{c l}-T_{a}\right)^{0.25} \\
12.1 \sqrt{V_{\text {air }}}
\end{array} \quad \text { for } 2.38\left(T_{c l}+T_{a}\right)^{0.25} \geq 12.1 \sqrt{V_{\text {air }}}\right.
\end{aligned}
$$

Where: $P M V$ is the Predicted Mean Vote, $M$ is the Metabolism $\left(W / m^{2}\right), W$ is the External work $\left(W / m^{2}\right)$, $I_{c l}$ is the Thermal resistant of clothing (clo), $f_{c l}$ is the Ratio of body surface area when fully clothed to body's surface area when nude. $V_{\text {air }}$ is the Relative air velocity $(\mathrm{m} / \mathrm{s}), P_{a}$ is the Partial water vapour pressure $\left(\mathrm{N} / \mathrm{m}^{2}\right)$, $h_{c}$ is the Convectional heat transfer coefficient $\left(W m^{-2} K\right), T_{a}$ is the Ambient air temperature $\left({ }^{0} \mathrm{C}\right)$, $T_{m r t}$ is the Mean radiant temperature $\left({ }^{\circ} \mathrm{C}\right), T_{c l}$ is the Surface temperature of clothing $\left({ }^{\circ} \mathrm{C}\right), T_{3}$ is the Outdoor and indoor wet bulb temperature $\left({ }^{\circ} \mathrm{C}\right)$ and $T_{L}$ is the Leaving air temperature $\left({ }^{\circ} \mathrm{C}\right)$.

\subsection{Predicted Percentage Dissatisfied}

The Predicted Percentage Dissatisfied (PPD) model is used to estimate the thermal comfort satisfaction of occupants in a space. It is considered that satisfying $80 \%$ of occupants is good. That is, PPD less than $20 \%$ is $\operatorname{good}[7]$.

$$
\begin{gathered}
P P D=100-95 \exp \left(-0.03353 P M V^{4}\right. \\
\left.+0.2179 P M V^{2}\right)
\end{gathered}
$$

\section{SATURATION EFFECTIVENESS}

The saturation effectiveness $\varepsilon_{\text {sat }}$, is the index used to assess the performance of a direct evaporative cooling and it is defined as ${ }^{[4]}$ :

$$
\varepsilon_{\text {sat }}=\frac{T_{a}-T_{L}}{T_{a}-T_{3}}
$$

The saturation effectiveness is a function of the type of cooling pad that is employed. Studies have shown that different cooling pads have different saturation effectiveness and the saturation effectiveness to a very large extent depends on the mass flow rate of air passing through the pad[9]. The saturation effectiveness of cellulose, corrugated paper pads, jute fiber, aspen pads, high density polythene pads, and coconut coir pads, range from $57 \%$ to $88 \%$ for air mass flow rate between $0.3 \mathrm{~kg} / \mathrm{s}$ to $0.9 \mathrm{~kg} / \mathrm{s}$ [9][12]. Therefore, a cooling pad material of $75 \%$ is considered in this study.

\section{METHODOLOGY}

The direct evaporative cooling potential of Enugu, Kano, Jos, Maiduguri and Mubi-South were estimated using the Predicted Percentage Dissatisfied (PPD) model. The predictive mean votes (PMV) of the study areas for the period of twelve months, January through December, were computed and the values obtained were used to determine the PPD for the corresponding months. In this study, the pertinent past weather data of the study areas obtained from NASAL 81 averaged over several years were used.

\subsection{Leaving Air Temperature}

Using equation 5 , the leaving air temperature, $T_{L}$, that is the air supplied from the direct evaporative cooler to the leaving space for the months of January through December were determined from equation 5 and 6 .

$$
T_{L}=T_{a}-\varepsilon_{\text {sat }}\left(T_{a}-T_{3}\right)
$$

For the selected cities, the corresponding wet bulb temperatures and the partial vapour pressure of the leaving air were determined from pschrometric chart and steam table.

\subsection{The Reduced Fanger's Comfort Equation}

In reducing the Fanger's comfort equation suitable for the application in conditioned space provided by direct evaporative coolers, the following assumptions were made:

i. Mean radiant temperature equal to the ambient air temperature $\left(T_{m r t}=T_{a}\right)$

ii. Surface temperature of clothing equal to the mean radiant temperature $\left(T_{c l}=T_{m r t}\right)$

iii. External work (metabolic free energy production) equal to zero

Based on the aforementioned assumptions, the reduced Fanger's comfort equation is then expressed as:

$$
\begin{aligned}
P M V=(0.028+ & \left.0.3033 e^{-0.036}\right)\{M \\
& -3.05\left[5.733-0.0000699 M-P_{a}\right] \\
& -[0.42 M+24.42] \\
& -0.0173\left(5.867-P_{a}\right) \\
& \left.-0.0014 M\left(34-T_{a}\right)\right\}
\end{aligned}
$$

The pertinent parameters of the indoor conditioned space were then used as the input values for the determination of the Predicted Mean Vote (PMV) using the reduced Fanger's equation (eq. 7). The PMV values for January through December were then used to determine the PPD values using equation 4. The 
computed values of the PPD for the months of January through December of the selected cities are shown in Figure 3- 6.

\section{RESULTS AND DISCUSSION}

The outdoor conditions, the determined indoor conditions and the corresponding PPD values computed for the months of January through December of the selected cities are shown in Figures 4 to 8. From Figure 4, it can be seen that in Enugu, only two months, January and December are suitable for the use of direct evaporative coolers based on the PPD model.

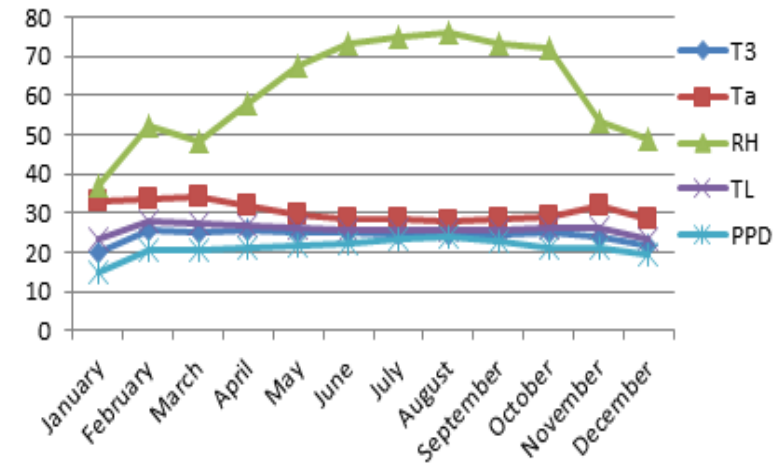

Figure 4: Outdoor and Indoor Conditions, and PPD of Jan - Dec of Enugu

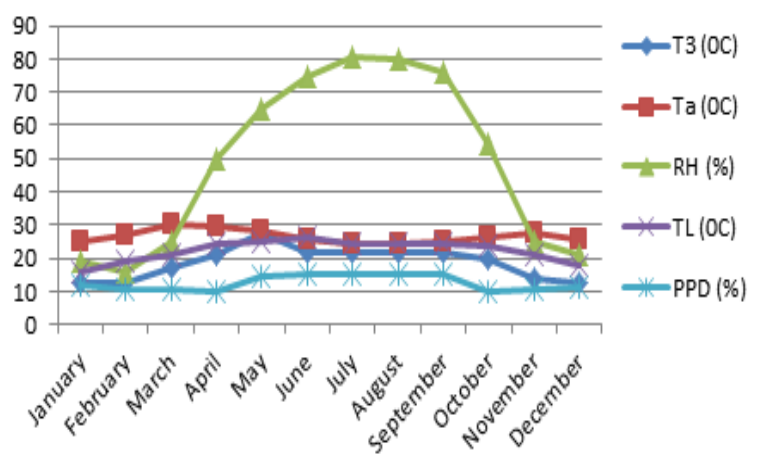

Figure 5: Outdoor and Indoor Conditions, and PPD of Jan - Dec of Kano

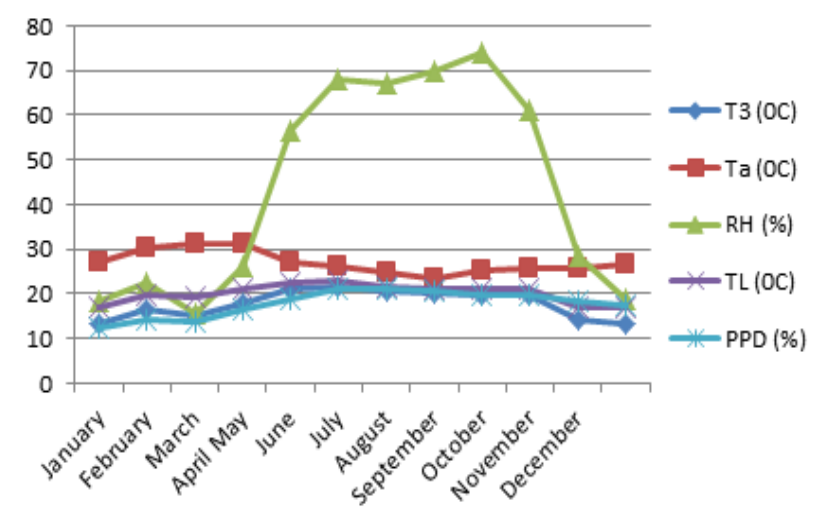

Figure. 6: Outdoor and Indoor Conditions, and PPD of Jan-Dec of Jos

Nigerian Journal of Technology,

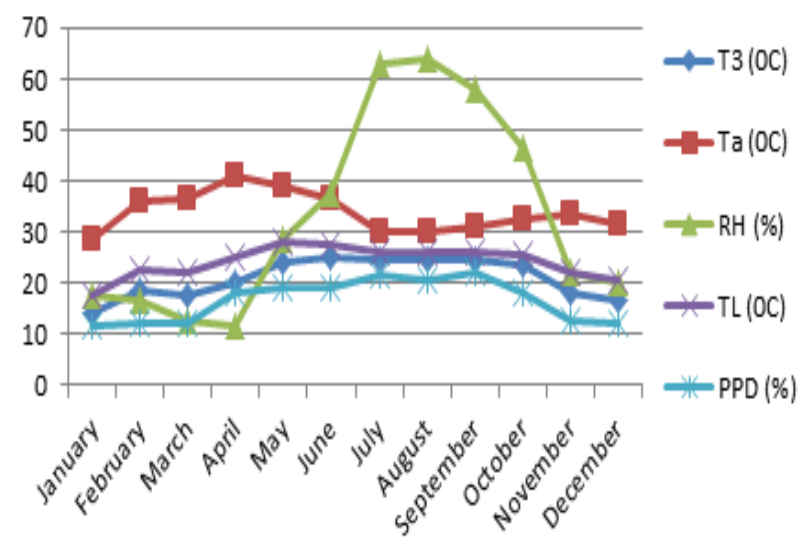

Figure 7: Outdoor and Indoor Conditions, and PPD of Jan - Dec of Maiduguri

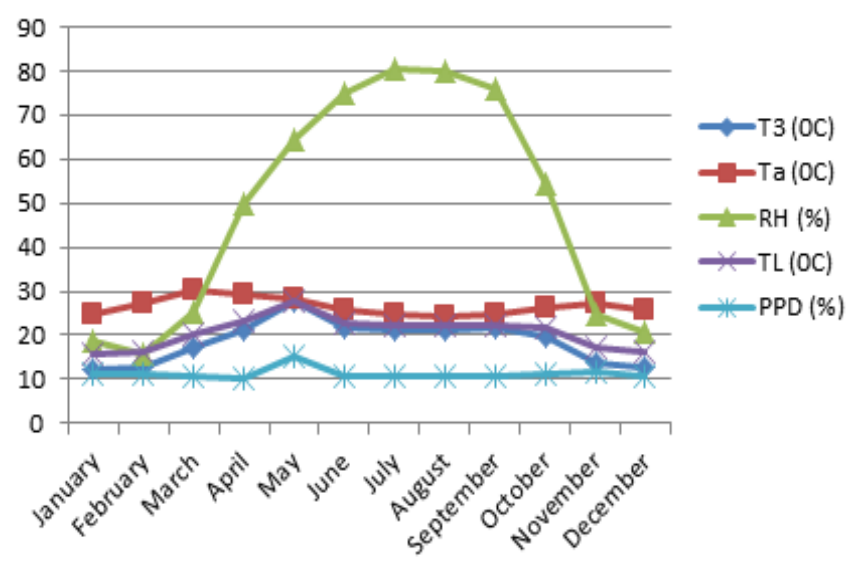

Figure 8: Outdoor and Indoor Conditions, and PPD of Jan - Dec of Mubi-South

This can however be attributed to the high ambient relative humidity in the remaining months. In the case of Kano and Mubi-South, the PPD values in all the months are less than $20 \%$ as shown in Figures 5 and 8. This implies that Kano and Mubi-South are suitable for the use of direct evaporative coolers. This agreed with the work of Camrago et al[10] that direct evaporative coolers perform better in hot and dry climates. From Figures 6 and 7, it can be seen that it is not suitable to use direct evaporative coolers in the months of June, July and August in Jos, and, July, August and September in Maiduguri. These months are characterized with relatively high relative humidity and low temperatures. This is in consonance with the work of Kulkarni et al [12] that the performance of direct evaporative coolers is low at high ambient relative humidity and low dry bulb temperatures.

\section{CONCLUSION}

The direct evaporative cooling potential of some selected cities in Nigeria: Enugu, Kano, Jos, Maiduguri and Mubi-South were estimated using the Predicted

Vol. 37, No. 1, January 2018 
Percentage Dissatisfied (PPD) model. The theoretical analyses of these cities using the PPD model show that comfort cooling can be achieved using directive evaporative coolers in the months January and December in Enugu; January, February, March, April, May, September, October, November and December in Jos; January, February, March, April, May, June, October, November and December in Maiduguri; and in all the months in the case of Kano and Mubi-South.

Based on the PPD model, the applicability of direct evaporative coolers is suitable in areas with relatively high dry bulb temperatures and low relative humidity.

\section{REFERENCES}

[1] Ibrahim, U. H. and D. A. Aremu. Performance evaluation of evaporative cooler using the Predictive Mean Vote (PMV) model. International Journal of Scientific and Technology Research, vol. 2, issue 11, pp. $272-275,2013$.

[2] Ismail, A. R. Thermal comfort assessment: A case study at Malaysian car manufacturer. European Journal of Scientific Research. Vol. 27, No. 4 pp. $510-523,2009$.

[3] Cengel, Y. A., Heat Transfer: Practical Approach.. First Revised Edition. Tata McGraw-Hill Publishing Company Ltd, New Delhi, 2002.

[4] Ibrahim, U. I., Baba, A. A. and Ishaq, M.. Evaluation of the potential of evaporative cooling for human thermal comfort: A case study of Kano, Nigeria. Journal of Engineering and Applied Science, vol. 4, pp. $21-28$.
[5] Fanger, P. 0. Thermal Comfort. Danish Technical Press, Copenhagen, pp. $21-23,1970$.

[6] Roberto, Z. F., Gustavo, H. C. O. and Nathan, M. Predictive Controllers for Thermal Comfort Optimization and Energy Saving. Energy and Building, 40: 1353 - 1365, 2012, 2008.

[7] Hamdi, M., Lachiver, G. and Michand, F. A new predictive thermal sensation index of human response. Energy and Building, 29: 167 - 178, 1999.

[8] NASA Surface Meteorology and Solar Energy: Interannual Variability. http:/yr.no/Nigeria/ adamawa/mubi.htm

[9] Kulkarni, R. K. and Rajput, S. P. S., Theoretical performance analysis of jute fibre rope bank as media in evaporative coolers. Indian Journal of Science and Technology. Vol. 3, No. 10, pp. 1075 1080, 2010.

[10] Camrago, J. R., Ebinuma, C. D. and Cardoso, S.. Three methods to evaluate the use of evaporative cooling for human thermal comfort. Thermal Engineering, vol. 5, No. 02, pp. 09 - 15, 2006.

[11] ASHRAE Handbook of Fundamentals, American Society of Heating, Refrigerating, Air Conditioning Engineers. Inc., Atlanta.USa, 1993.

[12] R. K. Kulkarni and S. P. S. Rajput,. Comparative Performance Analysis of Evaporative Cooling Pads of Alternative Materials. International Journal of Advanced Engineering Sciences and Technologies, vol. 10, issue 2, 239-244, 2011. 